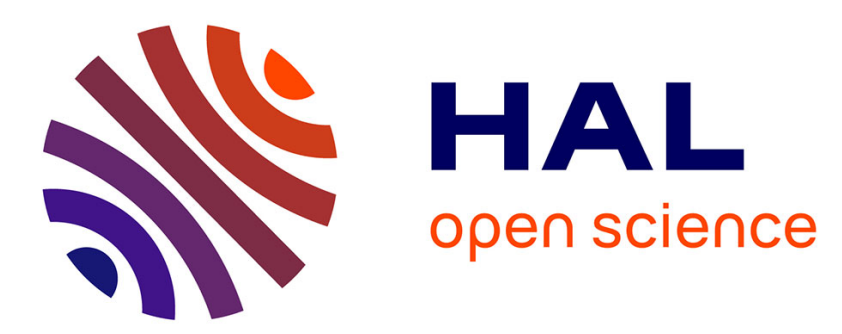

\title{
Designer substrates and devices for mechanobiology study
}

Wang Xi, Delphine Delacour, Benoit Ladoux

\section{To cite this version:}

Wang Xi, Delphine Delacour, Benoit Ladoux. Designer substrates and devices for mechanobiology study. Journal of Semiconductors, 2020, 41 (4), pp.041607. 10.1088/1674-4926/41/4/041607 . hal03453583

\section{HAL Id: hal-03453583 \\ https://hal.science/hal-03453583}

Submitted on 3 Dec 2021

HAL is a multi-disciplinary open access archive for the deposit and dissemination of scientific research documents, whether they are published or not. The documents may come from teaching and research institutions in France or abroad, or from public or private research centers.
L'archive ouverte pluridisciplinaire HAL, est destinée au dépôt et à la diffusion de documents scientifiques de niveau recherche, publiés ou non, émanant des établissements d'enseignement et de recherche français ou étrangers, des laboratoires publics ou privés. 


\title{
Designer substrates and devices for mechanobiology study
}

\author{
Wang Xi, Delphine Delacour, Benoit Ladoux \\ Cell adhesion and mechanics, Institut Jacques Monod, CNRS UMR7592, Paris Diderot \\ University, 75205 Paris Cedex 13, France
}

\begin{abstract}
Both biological and engineering approaches have contributed significantly to the recent advance in the field of mechanobiology. Collaborating with biologists, bio-engineers and materials scientists have employed the techniques stemming from the conventional semiconductor industry to rebuild cellular milieus that mimic critical aspects of in vivo conditions and elicit cell/tissue responses in vitro. Such reductionist approaches have help to unveil important mechanosensing mechanism in both cell and tissue level, including stem cell differentiation and proliferation, tissue expansion, wound healing, and cancer metastasis. In this mini-review, we discuss various microfabrication methods that have been applied to generate specific properties and functions of designer substrates/devices, which disclose cellmicroenvironment interactions and the underlying biological mechanisms. In brief, we emphasize on the studies of cell/tissue mechanical responses to substrate adhesiveness, stiffness, topography, and shear flow. Moreover, we comment on the new concepts of measurement and paradigms for investigations of biological mechanotransductions that are yet to emerge due to on-going interdisciplinary efforts in the fields of mechanobiology and microengineering.
\end{abstract}

\section{Introduction}

Designer substrates and devices have long been the heart of biomaterials, bioengineering, and a powerful tool for developmental biology, cell biology, biomedical studies. Especially, the high-cost of animal models and their concomitant long experimental cycle, ethical issues and poor reproducibility have cried out for in vitro substrates that mimic various in vivo conditions and tissue functions. The past decade has witnessed a surge in the interdisciplinary efforts in soft lithography, bio-inspired microfabrication, biochemistry and cell biology, allowing the design and production of sophisticated platforms that are capable to recapitulate natural contexts and elicit physiologically relevant events outside the body (Figure 1). This emerging field that studies cell and tissue mechanics with biological and engineering approaches is coined as mechanobiology. Progress in this field has shed light on important biological processes of live systems at the interface of biology and artificial substrates, which are directly related to the design and advance of next generation biomaterials, biomedical devices, and large scale tissue engineering ${ }^{1}$. 


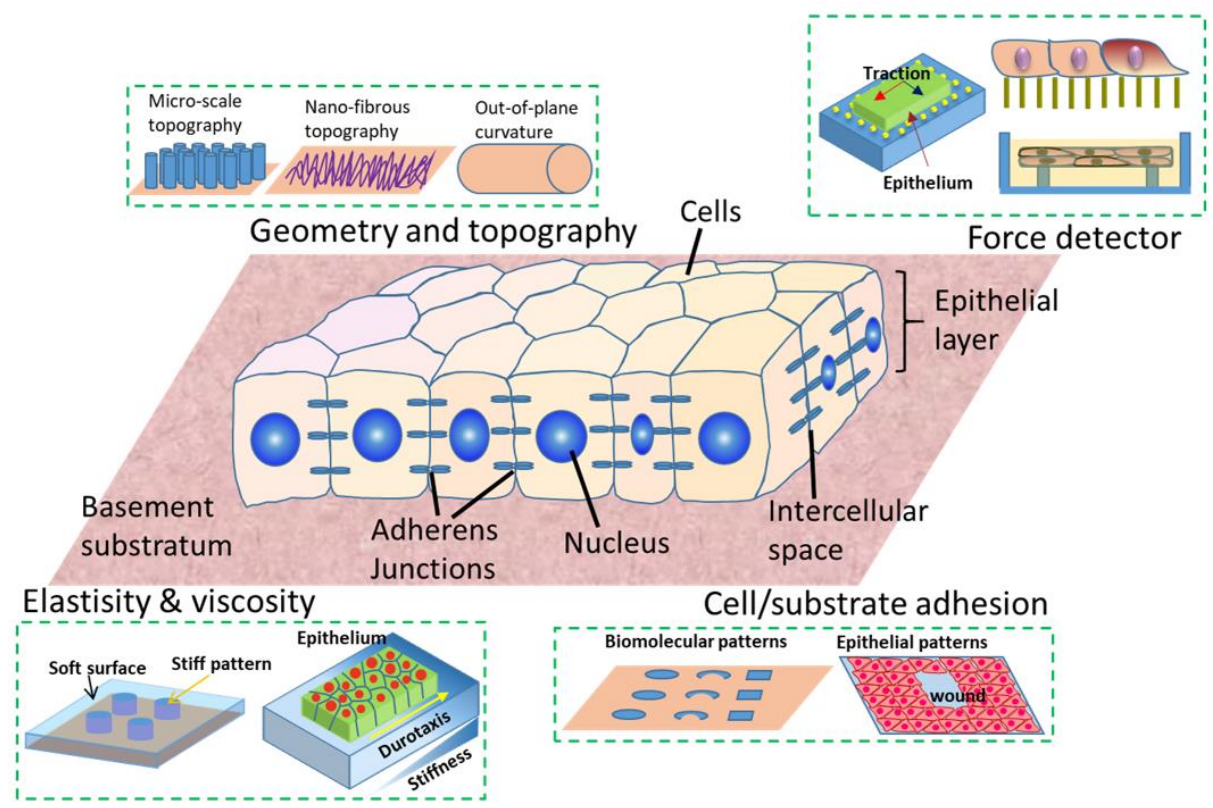

Figure 1. Microengineered synthetic substrates for cell/tissue mechanics studies. The properties of a substratum can be modified to adjust the cell/material interactions, such as surface topographies, stiffness, and adhesiveness. In addition, mechanical probes can be integrated into the substrate to detect the force in tissue. These include microbeads in the traction force microscopy and elastomeric micro-pillars.

Live systems are made of cells that can support tissue development and homeostasis through processes such as self-replication, renewal, selective destruction and sensing of the microenvironment. These processes require the cells to actively react to the environmental inputs, while having sufficient mechanical stability to sustain shape and function, and at the same time adequate fluidity for remodeling. Supported by increasing evidences from reconstituted molecular systems and single cell studies, it is now known that these active properties can be attributed at the molecular level through ATP consumption and in particular, by the activity of cell cytoskeleton and molecular motors ${ }^{2-4}$. For instance, the active remodeling of the actin cytoskeleton and the contractility of the stress fibers have been found to influence cell adhesion ${ }^{5,6}$, cell migration ${ }^{7-10}$, cell differentiation ${ }^{11}$, and cell polarity ${ }^{12,13}$, and can lead to the cellular sensing of their microenvironment, such as the sensing of substrate stiffness ${ }^{14-16}$, substrate curvature ${ }^{17-21}$, stretch ${ }^{22,23}$ and $\operatorname{shear}^{24}$. At the tissue level, the cells that constitute the cohort can be seen as individual agents that actively interact among themselves through cellcell junctions and with their local milieu via the cell-substrate adhesions to give rise to complex, emergent tissue responses ${ }^{25}$. Hence, unlike a passive system, the response of tissues promotes nonequilibrium properties ${ }^{26}$, later resulting in numerous synergistic cell behaviors that dictate many important tissue processes as observed in vivo and in vitro.

Such cell/tissue mechanosensing behaviors are influenced by a plethora of biochemical and biophysical cues ${ }^{1}$, such as adhesive sites, geometry, stiffness, and confinement that are ubiquitous in cellular microenvironment. One main goal of mechanobiology is to offer insights about how cell/tissue interprets these complicated and often intertwisted cues to commit to 
distinct fates. Hence, though it is within the realm of biology, the other side of the coin often relies on numerous bioengineering, reductionist approaches to rebuild cellular milieu and to elicit cell/tissue responses in vitro (Figure 1). In particular, technologies developed from the field of semiconductor, including soft-lithography, microcontact printing $(\mu \mathrm{CP})$, dry/wet etching, strain engineering, and microfluidics have enabled the production of various biomimetic substrates and devices, modulation of cell behaviors and unprecedented insights into tissue-level mechanotransduction. For example, different adhesive and stiffness patterns were made by lithography and micropatterning to unveil the mechanisms of durotaxis in fibroblasts ${ }^{27}$ and epithelia ${ }^{28}$, differentiation in stem cells ${ }^{29}$, and extrusion in an epithelium ${ }^{30}$. More complicated tridimensional (3D) scaffolds have also been fabricated by etching and molding to mimic tissue architectures and disease phenotypes ${ }^{31,32}$. Furthermore, functional micro-devices including microfluidics chips ${ }^{33-36}$ and self-folding $3 \mathrm{D}^{37-39}$ scaffolds have begun to unravel distinctive mechanical principles in cell migration, cancer metastasis, and proliferation.

In this review, we discuss how specific properties and functions of designer substrates/devices are achievable by various microfabrication methods and explain how underlying biological mechanisms due to cell-microenvironment interactions can be disclosed by these capabilities. In brief, we emphasize on semiconductor-based techniques that advance the study of cell/tissue mechanical responses to substrate adhesiveness, stiffness, topography, and shear flow. Moreover, we comment on the new concepts of measurement and paradigms for investigations of biological mechanotransduction that are yet to emerge due to on-going interdisciplinary efforts in the fields of mechanobiology and microengineering.

\section{Engineering substrate adhesion}

One important aspect of biologists' concerns is the cell/substrate interface and their interaction. Attachment of cells to a surface via adhesion complexes (ACs, Figure 2) provides important feedbacks that trigger a variety of signaling cascades and cellular behaviors. In vivo, cells take advantage of the heterogeneous distribution of extracellular matrix (ECM) cues to define many vital processes, such as wound healing ${ }^{40}$, metastasis ${ }^{41}$ and fibrosis ${ }^{42}$. To mimic such a surface chemistry property and to control assembly of ECM in vitro Whitesides group developed soft lithography (SL) in $1990 \mathrm{~s}^{43}$, whose derivative, known as $\mu \mathrm{CP}^{44}$ (Figure 3), quickly became a popular means to define the shapes and adhesive sites on a flat surface. This approach invokes the conventional photolithography tools and a mask to produce the master with patterns of high precision (down to several hundred nanometers). The lateral resolution can be further improved down to sub-10 nm with advanced technologies, for instance electron beam lithography. These prescribed features are mass-produced in almost any arbitrary shapes and transferred to stamps or stencils by molding, which can be later used to transfer biomolecules (e.g., proteins) to other surfaces by stamping or stenciling. In addition, with soft stamps and in some specific cases it is possible to print on out-of-plane curved substrates ${ }^{45}$. Though it is labor-intensive, the iteration 
of $\mu \mathrm{CP}$ process also allows transferring multiple proteins with high accuracy. The further development of surface patterning aims at improving the spatial resolution, switchable coating and 3D printing with ease. For example, block copolymer micelle nanolithography patterns gold nanoarrays on nonfouling background to control the distribution and position of individual transmembrane receptor integrin molecule ${ }^{29}$. Later, the advent of the combination of surface chemistry and light-activated patterning coined dynamic optical projection stereolithography ${ }^{46}$ (Figure 3) enables the dynamic coupling of proteins to 2D as well as 3D surfaces without a mask.

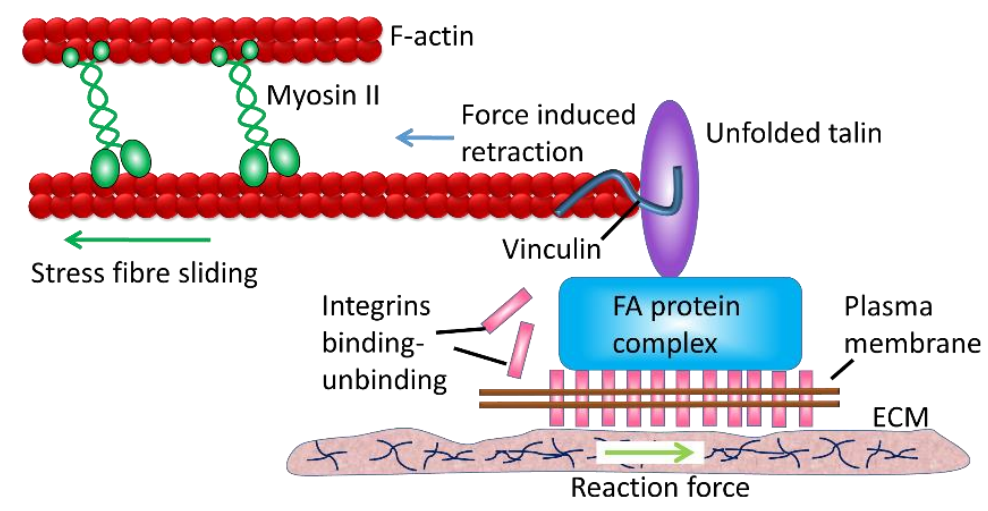

Figure 2. Molecular dynamics at adhesion complexes. The actin network as a mechanosensitive machine connecting the cell to its substrate and neighbors. (i) The building of a stable focal adhesion (FA) complex for cell-substrate adhesion. Actomyosin forces apply on the FA at a fixed speed and the rate of force increase in the complex increases proportionally with the ECM stiffness. To avoid the destabilization and detachment of the FA, the bindingunbinding dynamics of the transmembrane protein, integrin, that connects the cells to the substrate needs to be equal to the force loading rate in the complex. Another force buffer and mechanosensor in the complex is Talin. Its unfolding at $\sim 10 \mathrm{pN}$ at the normal rate of force loading in cells lead to vinculin binding to recruit more actin fibers, thus reinforcing the FA.

Patterning proteins is now made possible with multiple methods (Figure 3) and has become a routine technique in many biological studies. As early as late 1990s, the Ingber group used $\mu$ CP to constraint cells within arbitrary adhesive shapes containing fibronectin, a binding partner of integrin, and found that different areas of printing as well as its protein constituent results in dramatically modulation of cell growth and death ${ }^{47}$. It was then discovered that it is the transmitting of contractile forces by the interplay between cytoskeleton machinery and $\mathrm{ACs}^{48}$ (Figure 2) that lets the cells to "feel" their surroundings and triggers the onset of a range of molecular pathways, underpinning the fates of cells. Along this line, unprecedented insight into cell-substrate interaction has been unveiled. Broadly speaking, in contact with ECM proteins, like fibronectin, cell-substrate adhesion is formed, mediated through integrin-based complexes called focal adhesions (FAs) ${ }^{49}$. Once anchored on a surface, the FA is subjected to a traction force to resist cytoskeletal tension ${ }^{50}$. We now know that the stress at a single FA is of the order

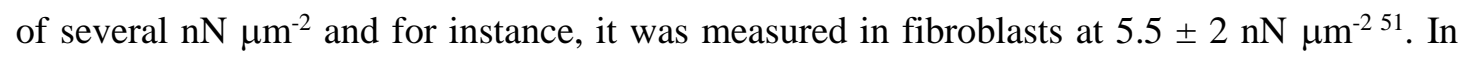
addition, Ha et al. found that during initial adhesion process a universal peak tension of $c a .40$ $\mathrm{pN}$ is applied to single integrin-ligand bonds by cells ${ }^{52}$. The mechanosensitive response is thus 
driven by protein unfolding under force and the exposure of cryptic sites for the binding of other proteins leading to adhesion reinforcement as exemplified by talin/vinculin binding in the FA (Figure 2). This mechanism allows FA to grow in size by sensing forces. Thus, as the cell spreads, the build-up of larger FAs correlates with higher traction forces. Indeed, smaller FAs and softer cytoskeletal network have been observed in rounded (less spreading) cells ${ }^{50}$, leading to cellular structural reorganization, which could have a lethal consequence ${ }^{47}$. In a multicellular context, this indicates the important role of local mechanical deformation of cell shape in tissue homeostasis, where cell density and crowding is balanced via both proliferation and extrusion. Additionally, given that many other organelles are also mechanically coupled to the FA through cytoskeleton network, the cell-substrate adhesion has a much broader impact on cellular behaviors, such as mitosis. This was demonstrated by the seminal work from Piel and colleagues $^{53}$ that retraction fibers that anchor to a substrate with pre-designed micropatterns exert directional strong forces on mitotic machinery and orientate the spindle by regulating actomyosin structures and microtubule dynamics.
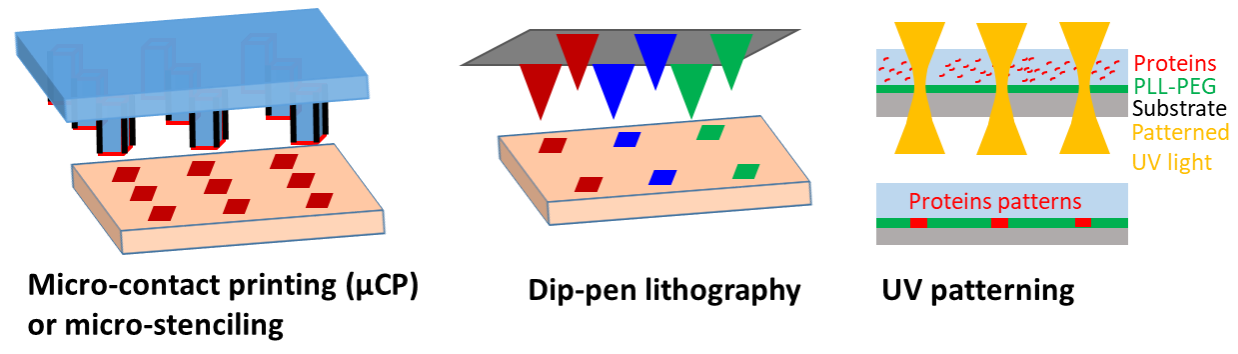

Figure 3. Methods for patterning adhesive surfaces. Semiconductor-based technologies has allowed the development of micro-contact printing and micro-stenciling for patterning biomolecules with define shapes. Later, researchers developed other techniques for this purpose, including Dip-pen lithography and UV-based patterning.

\section{Engineering substrate stiffness}

The fact that FA growth is coupled to the cell-substrate interaction leads to the postulation that cells tune their contractility according to the substrate rigidity. In this context, a series of methods have been developed to adjust substrate stiffness. Conventional approaches involve the modification of the cross-linking degree of the gels (Figure 4), including polyacrylamide (PAA) and polydimethylsiloxane (PDMS). Typically, their Yong's modulus can be changed over at least two orders of magnitudes, i.e., from 1 to $100 \mathrm{kPa}$, which is overlapping with the rigidity range of in vivo tissues ${ }^{54}$. Alternatively, another elegant means to modify surface stiffness is synthetic elastomeric micropost array ${ }^{15}$ (Figure 4). Produced by conventional SL, uniform arrays of microposts with different shape and length lie the affinity surface for cell. The bending of each post due to the lateral force applied by cells reflects the nature of traction force is trackable, and thus provides a simple way for the measurement of traction forces in cells/tissues ${ }^{15,55}$. Furthermore, by producing arrays of micropost with specific geometry, such as oval cross-section, one can generate a substrate exhibiting anisotropic local stiffness ${ }^{56}$. 


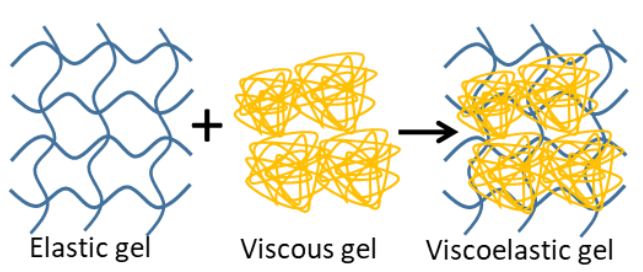

Viscoelastic gel

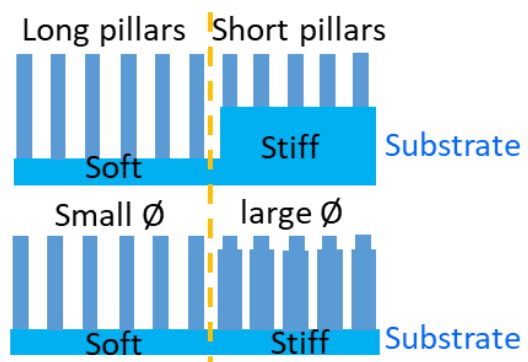

Pillar arrays

Figure 4. Methods for engineering substrate elasticity and viscosity. Conventionally, by controlling the cross-linking degree in elastomers, one could adjust the viscoelasticity of a gel. Another approach to change substrate rigidity involving photolithography is to pattern pillars of different shapes.

As discussed above, most types of cells response to the resistance via their attachment to a surface. Light resistance on a soft, flexible substrate will not stretch the force-bearing proteins, e.g., talin and vinculin, and leads to diffuse and dynamic $\mathrm{ACs}^{57}$. On the other hand, high resistance on a stiff substrate will unfold the adaptor proteins located within the adhesion, enhancing the $\mathrm{ACs}^{57,58}$. As a result, bigger and more stable FAs lead to more spreading and traction on a rigid surface than a soft one. This mechanism causes cells to move preferentially towards a stiffer substrate ${ }^{15,59}$, a phenomenon coined durotaxis. Along this line, a large cohort of cells that connect together via cell-cell adhesion has also been found to a range of rigidity gradients where single cells do not respond ${ }^{60}$. In fact, the cohort behaves like a giant cell that can transmit forces through the cell-cell junctions over a larger distance within the monolayer than single cells. These discoveries may have offered important indications in disease and development where cells translocate due to different material characteristics in various tissues ${ }^{61}$. Further, other important roles of substrate rigidity in regulating cell fates and functions include the modulation of nuclear mechanics and genetic expression that determine stem cell differentiation ${ }^{11}$ and the promotion of epithelial-mesenchymal transition of invading epithelial cancer cells ${ }^{62}$.

\section{Engineering substrate topography}

Many biological studies are still carried out on planar and featureless substrates, while perfectly flat surfaces do not usually exist in vivo. Instead, cells in physiological environment often experience complex 3D architectures and out-of-plane curvatures. To mimic in vivo situations and to study cell interactions with these features, cells are seeded on synthetic substrate harboring precise surface topographies. In general, photolithography is combined with etching techniques to create prescribed 3D topographic structures and later, functional substrates are produced using replica molding from masters ${ }^{31}$. Other microfabrication methods, such as strain engineering ${ }^{63}$, can also generate 3D microstructures. This technique patterns pre-strained, 
flexible nanofilm of various shapes on top of a sacrificial layer. The latter was later underetched to release the nanofilm, which self-folds into complex 3D architectures by its intrinsic strain. In principle, a vast topographical diversity can be generated using elastomeric polymers, for example, PAA and PDMS, deformable semiconductor materials and even rigid metal materials ${ }^{63}$. The photolithography-based approaches also allow the integration of electronic and optical functions for novel biological microelectromechanical systems (Bio-MEMS).

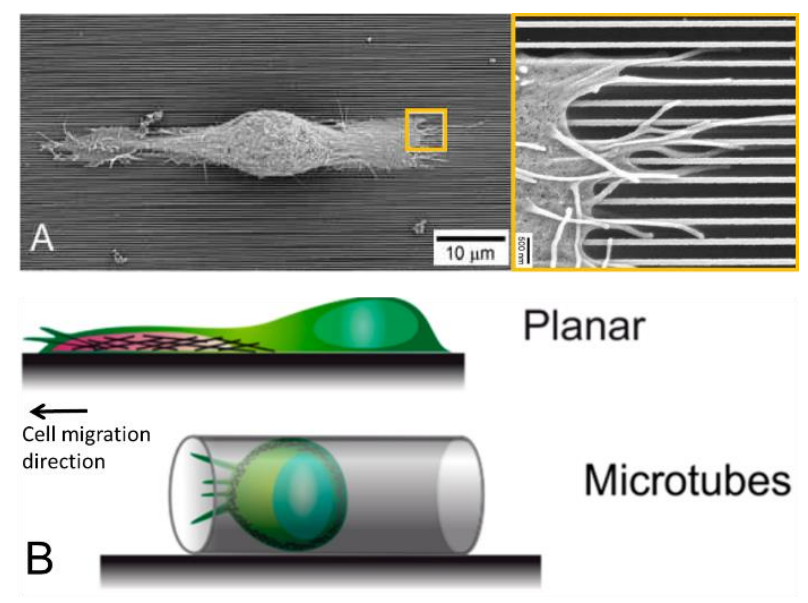

Figure 5. Topography cues influences cell adhesion and migration. A) Scanning electron micrographs (SEMs) showing cells aligned to the nano-lines (Reproduced from ref. 64). B) 3D confinement, such as microtubes, leads to amoeboid-like migration mode in neural stem cells (Reproduced from ref. 39).

Previous studies revealed that cellular FAs have a broad range of size from about $10 \mathrm{~nm}$ to 10 $\mu \mathrm{m}$, suggesting cell may employ dynamic FA mechanism to sense the topographical cues. For instance, cell migratory dynamics changes on an array of $10 \mu \mathrm{m}$ size micropillars, where the cells move slower with higher persistence in comparison with that on a flat surface ${ }^{64}$. Other concomitants include re-organization of the actin cytoskeleton and FAs, prolonged FA life-time, and diversified myosin II activity ${ }^{64,65}$. Nanoscale features also influence cell adhesion and morphology. By seeding smooth muscle cells on PDMS nano-grooves, researchers have demonstrated that the cells tend to align along the longitudinal direction of the lines ${ }^{66}$ (Figure 5A). Using rolled-up strain-engineered nanofilm, the Schmidt group has produced microtubes that confine motile neural stem cells (NSCs). They found that 3D tubular configuration limited the spreading of NSCs and cause the cells to adapt an amoeboid-like migration mode ${ }^{39}$ (Figure 5B). Furthermore, the advantage of SL enables the creation of on-chip micro-scaffolds to guide the tissue-level morphogenesis. For example, villi and crypts laden with epithelia have been fabricated via simple steps of casting and curing of organic polymers on a master ${ }^{31,32}$. With this approach, a recent study discovered the importance of tissue-level contractility in maintaining epithelial tissue integrity, as compromise in cell-cell adhesion disturbs the overall stress field and leads to the development of a disease phenotype ${ }^{31}$. These examples reveal that controlling 
material properties could offer a means to gain insights about how cells interpret topographical cues in physiological conditions.

\section{Microfluidic chip}

One major goal of bioengineering is to establish in vitro models that emulate the architecture, function, microenvironment, and physiological processes of living tissues. The aforementioned techniques show various advantages in understanding various mechano-properties of cells/tissues, but they also face limitations. Recently, with advanced microfabrication methods there is a surge in the integration of multiple moduli that provide controls to various biochemical/physical cues into a single microfluidic chip ${ }^{67}$. This technique allows gaining control of the flow of minute amount of liquid by perfusing fluid into microchannels. Later, many derivative approaches, such as organ-on-a-chip, sprung up due to the collaborative efforts of biologists and engineers to laden the channels with cells. One advantage of microfluidics is that it generates various types of flow ranging from laminar stream to turbulence ${ }^{67}$, more akin to a series of in vivo situations for mimicking fluid-tissue interactions. Thus, some in vivo challenges faced by epithelia as well as endothelial layers, such as fluid shear stress, biochemical/pathogen concentrations, and osmotic pressure can be conveniently recapitulated ${ }^{68-70}$.

The fluid shear stress is due to the flow imposed on the tissues such as epithelial sheets that line ducts and endothelia that line the vessels. Epithelial cells sense fluid flow via their primary cilia - as the primary cilia are bended, the $\mathrm{Ca}^{2+}$-signaling pathway is elicited ${ }^{71,72}$. Using microfluidic chips, a previous study has confirmed that the cytoskeleton network of an epithelium that is subjected to continuous fluid shear is under mechanical stress ${ }^{73}$. Such stress within the monolayer can then cause cytoskeleton rearrangement and adherens junction (AJ) enhancement (Figure 6A), leading to a tighter layer ${ }^{74-76}$. Arguably, the most studied fluid shear-induced mechanobiology response is the endothelial-hemodynamic interaction related to the atherosclerosis disease, where arterial blockage happens due to plaque buildup. Specifically, straight sections within the artery promote laminar blood flow that in turn induces endothelial cell alignment with the flow ${ }^{77}$. Cellular-flow alignment is found to be important in activating endothelial nitrous oxide (NO) production crucial for the prevention of atherosclerosis progression $^{78}$. In contrast, atherosclerosis forms preferentially at arterial bifurcations with disturbed flow and reduced collective cell alignment. The mechano-sensing of shear flow in endothelial cells (ECs) involves molecular mechano-sensors such as the proteoglycan Syndecan- 4 at the surface of ECs ${ }^{79}$ and the cell-cell junctional protein PECAM- ${ }^{80}$ at the endothelial AJ showing the importance of cell-collectivity in this process. 
A

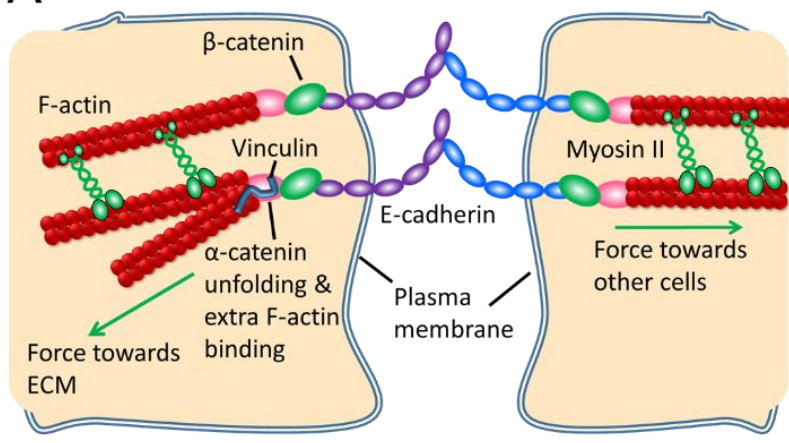

B

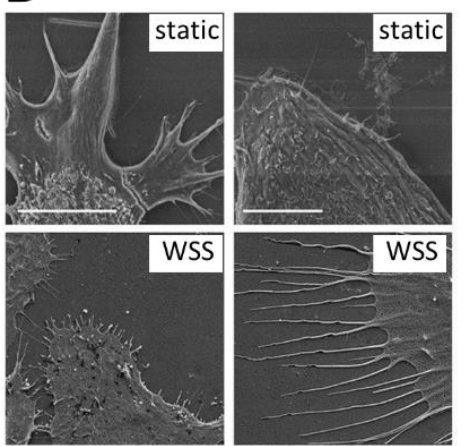

Figure 6. Shear stress influences cell adherens junction (AJ) and filopodia protrusion. A) At $A J s$, a higher force transmitted from F-actin caused by other factors (such as shear) leads to $\alpha$-catenin unfolding and subsequently the recruitment of vinculin to stabilize the AJ structure. B) SEMs showing filopodia formation in human cancer cells in response to wall shear stress (WSS) (Reproduced from ref. 82).

Such active behaviors have been attributed to active cellular force distribution changes under static or flow conditions measured using traction force microscopy (TFM), micropillars and/or FRET bio-sensor techniques ${ }^{80,81}$ (Figure 1). For example, cell-substrate traction and intercellular stress are found to re-align first with flow direction, followed by a slower EC cell body reorientation with flow ${ }^{81,82}$. At the same time, a flow-induced elevated molecular tension in PECAM-1 is thought to activate the Src family kinase pathway and NO production ${ }^{80}$. Interestingly, even though PECAM-1 experiences higher tension, the overall intercellular stress was found to drop instead during flow and this is found to be related to VE-cadherin-junctional remodeling. This overall decrease of the intercellular stress and junctional tension could retain the integrity of cell-cell junctions and maintain EC barrier function. Further, the crucial effects of the cell collectivity in driving large-scale EC-alignment under flow is most clearly seen in experiments showing that isolated ECs elongate their cell body in response to flow, but do not align with their neighbors in contrast to those in a confluent monolayer ${ }^{83}$.

Moreover, cancer cell migration and invasion can also be stimulated by hydrodynamic currents in the form of lymphatic flows experienced by cancers cells that have spread into the lymphatic system, and interstitial flows between the ECM of tissues. It was found that wall shear stress few orders of magnitude lower than that experienced by ECs ( 1 Pa for ECs) induced by flow on a dense but non-confluent layer of PC3 prostate cancer cells on the inner collagen-coated surfaces of a cylindrical PDMS tube, could stimulate Yes-associated protein (YAP) activation and increase filopodia protrusion and migration ${ }^{84}$ (Figure 6B). In a different setting, sparse populations of breast cancer cells MDA-MB-231 embedded in collagen I gel was induced to migrate along interstitial flows (typical flow speeds of $\sim 0.3 \mu \mathrm{m} / \mathrm{s}$ ) and this was found to be due to the flow-assisted autologous chemical gradient establishment involving the cell-secreted ligand and its CCR7 receptor ${ }^{85}$. Interestingly, an increased cell density reduced this migration behavior with flow, probably due to the local chemical gradient around each cell being 
overwhelmed by ligands secreted by neighboring cells. Further, higher flows $(\sim 3 \mu \mathrm{m} / \mathrm{s})$ induced cells to migrate against flow as evidences show that an integrin-dependent signaling is activated by higher shear to compete with the autologous chemotaxis ${ }^{85}$. In a collective solid tumor setting of MDA-MB-231, an increased interstitial fluid pressure $(\sim 1.2 \mathrm{~mm} \mathrm{Hg}$ pressure differential between tumor tip and base) triggered multicellular cell chains to invade at the tumor tip where the pressure is higher, similar to the migration against flow observed for single cell conditions ${ }^{86}$. This was related to the elevation of EMT markers within cells such as Snail and vimentin. Surprisingly, the increased expression of E-cadherin was crucial for this collective invasion even though EMT is usually associated with the down-regulation of Ecadherin. Taken together, the "microfluidic organs-on-chips" systems offer a powerful platform to spatiotemporally regulate and study different critical parameters that are important for tissue mechanotransduction.

\section{Outlook}

The recent advancement of mechanobiology has been largely based on the rapid development of material microfabrication and engineering methods to recapitulate aspects of in vivo cell/tissue milieus. Microenvironmental factors, including the surface affinity to cells, substrate rigidity and topography, as well as shear flow have been found to contribute significantly for cell adhesion, migration, polarization, and differentiation. Our ability to independently control a range of parameters has offered unprecedented insight into cell/tissue mechanical properties. This is further combined with conventional cell biology approaches, which results in many discoveries in novel molecular pathways that are related to various mechanosensing mechanisms. The latest efforts in this field begin to focus on even more complex microenvironmental controls ${ }^{88}$, such as developing anisotropic materials with 3D topographic cues and time-evolving substrates. Indeed, the cellular environment contains a plethora of influential factors that cells encounter and decipher. Since time scales are important in cell behaviors, specific cell functions could be defined by adapting optimal properties of the substrate. Hence, a platform that can simultaneously and independently modulate different parameters will surely improve our understanding of the cause-and-effect of cell processes in complicated contexts, and is highly sought-after. This challenge is currently addressed by interdisciplinary approaches to generate novel substrates that consist of heterogeneous ECM biocomposites and adjustable material properties by light, temperature, $\mathrm{pH}$, and biochemistry. Microfabrication methods will be helpful in integrating these important advancements into smart bio-chips and achieving a system that extends the current relatively short-term mechanobiology studies to the investigations of long-term effects of mechanical factors in development, disease and functions. Furthermore, Bio-MEMS can provide high-throughput screening with integrated bio-sensors. In short, the innovations in microfabrication will continuously advance our ever-growing knowledge in the field of mechanobiology in the future. 


\section{Acknowledgement}

The authors thank T. B. Saw and C. T. Lim from the Mechanobiology Institute, Singapore and the members of CAML group at Institut Jacques Monod, Paris for fruitful discussions. Financial supports from the European Research Council (ERC) under the European Union's Seventh Framework Programme (FP7/2007-2013) / ERC grant agreement numbers 617233 (B.L.), Marie Skłodowska-Curie Actions (W.X., Individual Fellowship, Project: 846449), the Groupama Foundation - Research Prize for Rare Diseases 2017 (to D.D), the Fondation pour la Recherche Médicale (FRM) (to D.D.), the LabEx “Who Am I?" \#ANR-11-LABX-0071 and the Université de Paris IdEx \#ANR-18-IDEX-0001 funded by the French Government through its "Investments for the Future" program (to D.D), and the Human Frontier Science Program (RGP0038/2018) (to D.D) are gratefully acknowledged.

1 Xi, W., Saw, T. B., Delacour, D., Lim, C. T. \& Ladoux, B. Material approaches to active tissue mechanics. Nat. Rev. Mater. 4, 23-44 (2019).

2 Prost, J., Jülicher, F. \& Joanny, J.-F. Active gel physics. Nature Physics 11, 111 (2015).

3 Marchetti, M. C., Joanny, J.-F., Ramaswamy, S., Liverpool, T. B., Prost, J., Rao, M. \& Simha, R. A. Hydrodynamics of soft active matter. Reviews of Modern Physics $\mathbf{8 5}$, 1143 (2013).

$4 \quad$ Needleman, D. \& Dogic, Z. Active matter at the interface between materials science and cell biology. Nature Reviews Materials 2, 17048 (2017).

5 Grashoff, C., Hoffman, B. D., Brenner, M. D., Zhou, R., Parsons, M., Yang, M. T., Mclean, M. A., Sligar, S. G., Chen, C. S., Ha, T. \& Schwartz, M. A. Measuring mechanical tension across vinculin reveals regulation of focal adhesion dynamics. Nature 466, 263-266 (2010).

6 Giannone, G., Dubin-Thaler, B. J., Döbereiner, H.-G., Kieffer, N., Bresnick, A. R. \& Sheetz, M. P. Periodic Lamellipodial Contractions Correlate with Rearward Actin Waves. Cel/ 116, 431-443 (2004).

7 Ray, A., Lee, O., Win, Z., Edwards, R. M., Alford, P. W., Kim, D.-H. \& Provenzano, P. P. Anisotropic forces from spatially constrained focal adhesions mediate contact guidance directed cell migration. Nature Communications 8, 14923 (2017).

8 Jiang, X., Bruzewicz, D. A., Wong, A. P., Piel, M. \& Whitesides, G. M. Directing cell migration with asymmetric micropatterns. Proceedings of the National Academy of Sciences of the United States of America 102, 975-978 (2005).

9 Chen, B., Kumar, G. \& Ho, C.-C. Geometric control of cell migration. Scientific reports 3, 2827 (2013).

10 Johnson, H. E., King, S. J., Asokan, S. B., Rotty, J. D., Bear, J. E. \& Haugh, J. M. Factin bundles direct the initiation and orientation of lamellipodia through adhesion-based signaling. J Cell Biol, jcb. 201406102 (2015). 
11 Engler, A. J., Sen, S., Sweeney, H. L. \& Discher, D. E. Matrix Elasticity Directs Stem Cell Lineage Specification. Cel/ 126, 677-689 (2006).

12 Naganathan, S. R., Middelkoop, T. C., Fürthauer, S. \& Grill, S. W. Actomyosindriven left-right asymmetry: from molecular torques to chiral self organization. Current opinion in cell biology 38, 24-30 (2016).

13 Tee, Y. H., Shemesh, T., Thiagarajan, V., Hariadi, R. F., Anderson, K. L., Page, C., Volkmann, N., Hanein, D., Sivaramakrishnan, S. \& Kozlov, M. M. Cellular chirality arising from the self-organization of the actin cytoskeleton. Nature cell biology 17, 445 (2015).

14 Gupta, M., Sarangi, B. R., Deschamps, J., Nematbakhsh, Y., Callan-Jones, A., Margadant, F., Mège, R.-M., Lim, C. T., Voituriez, R. \& Ladoux, B. Adaptive rheology and ordering of cell cytoskeleton govern matrix rigidity sensing. Nature communications 6, 7525 (2015).

15 Trichet, L., Le Digabel, J., Hawkins, R. J., Vedula, S. R. K., Gupta, M., Ribrault, C., Hersen, P., Voituriez, R. \& Ladoux, B. Evidence of a large-scale mechanosensing mechanism for cellular adaptation to substrate stiffness. Proceedings of the National Academy of Sciences 109, 6933-6938 (2012).

16 Zemel, A., Rehfeldt, F., Brown, A., Discher, D. \& Safran, S. Optimal matrix rigidity for stress-fibre polarization in stem cells. Nature physics 6, 468 (2010).

17 Levina, E. M., Domnina, L. V., Rovensky, Y. A. \& Vasiliev, J. M. Cylindrical substratum induces different patterns of actin microfilament bundles in nontransformed and in ras-transformed epitheliocytes. Experimental cell research 229, 159-165 (1996).

18 Svitkina, T. M., Rovensky, Y. A., Bershadsky, A. D. \& Vasiliev, J. M. Transverse pattern of microfilament bundles induced in epitheliocytes by cylindrical substrata. Journal of cell science 108, 735-745 (1995).

19 Sun, B., Xie, K., Chen, T.-H. \& Lam, R. H. Preferred cell alignment along concave microgrooves. RSC Advances 7, 6788-6794 (2017).

20 Biton, Y. \& Safran, S. The cellular response to curvature-induced stress. Physical biology 6, 046010 (2009).

21 Bade, N. D., Kamien, R. D., Assoian, R. K. \& Stebe, K. J. Curvature and Rho activation differentially control the alignment of cells and stress fibers. Science advances 3, e1700150 (2017).

22 De, R., Zemel, A. \& Safran, S. A. Dynamics of cell orientation. Nature Physics 3, 655 (2007).

23 Livne, A., Bouchbinder, E. \& Geiger, B. Cell reorientation under cyclic stretching. Nature communications 5, 3938 (2014).

24 Sidhaye, V. K., Schweitzer, K. S., Caterina, M. J., Shimoda, L. \& King, L. S. Shear stress regulates aquaporin-5 and airway epithelial barrier function. Proc. Natl. Acad. Sci. U.S.A 105, 3345-3350 (2008).

25 Ladoux, B. \& Mège, R.-M. Mechanobiology of collective cell behaviours. Nat. Rev. Mol. Cell Biol. 18, 743-757 (2017).

26 Prost, J., Jülicher, F. \& Joanny, J. F. Active gel physics. Nat. Phys. 11, 111 (2015). 
27 Wong, S., Guo, W.-H. \& Wang, Y.-L. Fibroblasts probe substrate rigidity with filopodia extensions before occupying an area. Proc. Natl. Acad. Sci. U.S.A 111, 17176-17181 (2014).

28 Saez, A., Ghibaudo, M., Buguin, A., Silberzan, P. \& Ladoux, B. Rigidity-driven growth and migration of epithelial cells on microstructured anisotropic substrates. Proc. Natl. Acad. Sci. U.S.A 104, 8281-8286 (2007).

29 Wang, X., Li, S., Yan, C., Liu, P. \& Ding, J. Fabrication of RGD Micro/Nanopattern and Corresponding Study of Stem Cell Differentiation. Nano Lett. 15, 1457-1467 (2015).

30 Saw, T. B., Doostmohammadi, A., Nier, V., Kocgozlu, L., Thampi, S., Toyama, Y., Marcq, P., Lim, C. T., Yeomans, J. M. \& Ladoux, B. Topological defects in epithelia govern cell death and extrusion. Nature 544, 212-216 (2017).

31 Salomon, J., Gaston, C., Magescas, J., Duvauchelle, B., Canioni, D., Sengmanivong, L., Mayeux, A., G, M., F, C., J, L., J, V., F, P., N, M., J, S., N, B., B, L., O, G. \& Delacour, D. Contractile forces at tricellular contacts modulate epithelial organization and monolayer integrity. Nat. Commun. 8, 13998 (2017).

32 Wang, Y., Gunasekara, D. B., Reed, M. I., DiSalvo, M., Bultman, S. J., Sims, C. E., Magness, S. T. \& Allbritton, N. L. A microengineered collagen scaffold for generating a polarized crypt-villus architecture of human small intestinal epithelium. Biomaterials 128, 44-55 (2017).

33 Stroka, Kimberly M., Jiang, H., Chen, S.-H., Tong, Z., Wirtz, D., Sun, Sean X. \& Konstantopoulos, K. Water Permeation Drives Tumor Cell Migration in Confined Microenvironments. Cel/157, 611-623 (2014).

34 Raab, M., Gentili, M., de Belly, H., Thiam, H.-R., Vargas, P., Jimenez, A. J., Lautenschlaeger, F., Voituriez, R., Lennon-Duménil, A.-M., Manel, N. \& Piel, M. ESCRT III repairs nuclear envelope ruptures during cell migration to limit DNA damage and cell death. Science 352, 359-362 (2016).

35 Denais, C. M., Gilbert, R. M., Isermann, P., McGregor, A. L., te Lindert, M., Weigelin, B., Davidson, P. M., Friedl, P., Wolf, K. \& Lammerding, J. Nuclear envelope rupture and repair during cancer cell migration. Science 352, 353-358 (2016).

36 Moreau, H. D., Blanch-Mercader, C., Attia, R., Maurin, M., Alraies, Z., Sanséau, D., Malbec, O., Delgado, M.-G., Bousso, P., Joanny, J.-F., Voituriez, R., Piel, M. \& Lennon-Duménil, A.-M. Macropinocytosis Overcomes Directional Bias in Dendritic Cells Due to Hydraulic Resistance and Facilitates Space Exploration. Developmental Cel/ 49, 171-188 (2019).

37 Xi, W., Schmidt, C. K., Sanchez, S., Gracias, D. H., Carazo-Salas, R. E., Jackson, S. P. \& Schmidt, O. G. Rolled-up Functionalized Nanomembranes as ThreeDimensional Cavities for Single Cell Studies. Nano Lett. 14, 4197-4204 (2014).

38 Xi, W., Schmidt, C. K., Sanchez, S., Gracias, D. H., Carazo-Salas, R. E., Butler, R., Lawrence, N., Jackson, S. P. \& Schmidt, O. G. Molecular Insights into Division of Single Human Cancer Cells in On-Chip Transparent Microtubes. Acs Nano 10, 5835-5846 (2016). 

O. G. Dimensionality of Rolled-up Nanomembranes Controls Neural Stem Cell Migration Mechanism. Nano Lett. 15, 5530-5538 (2015).

40 Maquart, F. X. \& Monboisse, J. C. Extracellular matrix and wound healing. Pathol. Biol. 62, 91-95 (2014).

41 Kobayashi, H., Enomoto, A., Woods, S. L., Burt, A. D., Takahashi, M. \& Worthley, D. L. Cancer-associated fibroblasts in gastrointestinal cancer. Nat. Rev. Gastroenterol. Hepatol. 16, 282-295 (2019).

42 Kleinman, H. K., Philp, D. \& Hoffman, M. P. Role of the extracellular matrix in morphogenesis. Curr. Opin. Biotech. 14, 526-532 (2003).

43 Xia, Y. N. \& Whitesides, G. M. Soft lithography. Angewandte Chemie-International Edition 37, 550-575 (1998).

44 Qin, D., Xia, Y. \& Whitesides, G. M. Soft lithography for micro- and nanoscale patterning. Nat. Protoc. 5, 491 (2010).

45 Xia, Y., Kim, E., Zhao, X.-M., Rogers, J. A., Prentiss, M. \& Whitesides, G. M. Complex Optical Surfaces Formed by Replica Molding Against Elastomeric Masters. Science 273, 347-349 (1996).

46 Strale, P.-O., Azioune, A., Bugnicourt, G., Lecomte, Y., Chahid, M. \& Studer, V. Multiprotein Printing by Light-Induced Molecular Adsorption. Adv. Mater. 28, 2024-2029 (2016).

47 Chen, C. S., Mrksich, M., Huang, S., Whitesides, G. M. \& Ingber, D. E. Geometric Control of Cell Life and Death. Science 276, 1425-1428 (1997).

48 Parsons, J. T., Horwitz, A. R. \& Schwartz, M. A. Cell adhesion: integrating cytoskeletal dynamics and cellular tension. Nat. Rev. Mol. Cell Biol. 11, 633-643 (2010).

49 Kanchanawong, P., Shtengel, G., Pasapera, A. M., Ramko, E. B., Davidson, M. W., Hess, H. F. \& Waterman, C. M. Nanoscale architecture of integrin-based cell adhesions. Nature 468, 580-584 (2010).

50 Wang, N., Butler, J. \& Ingber, D. Mechanotransduction across the cell surface and through the cytoskeleton. Science 260, 1124-1127 (1993).

51 Balaban, N. Q., Schwarz, U. S., Riveline, D., Goichberg, P., Tzur, G., Sabanay, I., Mahalu, D., Safran, S., Bershadsky, A., Addadi, L. \& Geiger, B. Force and focal adhesion assembly: a close relationship studied using elastic micropatterned substrates. Nat Cel/ Bio/3, 466-472 (2001).

52 Wang, $X . \& \mathrm{Ha}, \mathrm{T}$. Defining single molecular forces required to activate integrin and notch signaling. Science 340, 991-994 (2013).

53 Fink, J., Carpi, N., Betz, T., Bétard, A., Chebah, M., Azioune, A., Bornens, M., Sykes, C., Fetler, L., Cuvelier, D. \& Piel, M. External forces control mitotic spindle positioning. Nat. Cell Biol. 13, 771-778 (2011).

54 Discher, D. E., Janmey, P. \& Wang, Y.-I. Tissue Cells Feel and Respond to the Stiffness of Their Substrate. Science 310, 1139-1143 (2005).

55 du Roure, O., Saez, A., Buguin, A., Austin, R. H., Chavrier, P., Siberzan, P. \& Ladoux, B. Force mapping in epithelial cell migration. Proc. Natl. Acad. Sci. U.S.A 102, 2390-2395 (2005). 
Shao, Y. \& Fu, J. Integrated Micro/Nanoengineered Functional Biomaterials for Cell Mechanics and Mechanobiology: A Materials Perspective. Adv. Mater. 26, 1494-1533 (2014).

57 Pelham, R. J. \& Wang, Y.-I. Cell locomotion and focal adhesions are regulated by substrate flexibility. Proc. Natl. Acad. Sci. U.S.A 94, 13661-13665 (1997).

58 Sarangi, B. R., Gupta, M., Doss, B. L., Tissot, N., Lam, F., Mège, R.-M., Borghi, N. \& Ladoux, B. Coordination between Intra- and Extracellular Forces Regulates Focal Adhesion Dynamics. Nano Lett. 17, 399-406 (2017).

59 Mitrossilis, D., Fouchard, J., Guiroy, A., Desprat, N., Rodriguez, N., Fabry, B. \& Asnacios, A. Single-cell response to stiffness exhibits muscle-like behavior. Proc. Natl. Acad. Sci. U.S.A 106, 18243-18248 (2009).

60 Sunyer, R., Conte, V., Escribano, J., Elosegui-Artola, A., Labernadie, A., Valon, L., Navajas, D., García-Aznar, J. M., Muñoz, J. J., Roca-Cusachs, P. \& Trepat, X. Collective cell durotaxis emerges from long-range intercellular force transmission. Science 353, 1157-1161 (2016).

61 Paszek, M. J., Zahir, N., Johnson, K. R., Lakins, J. N., Rozenberg, G. I., Gefen, A., Reinhart-King, C. A., Margulies, S. S., Dembo, M., Boettiger, D., Hammer, D. A. \& Weaver, V. M. Tensional homeostasis and the malignant phenotype. Cancer Cell 8, 241-254 (2005).

62 Levental, K. R., Yu, H., Kass, L., Lakins, J. N., Egeblad, M., Erler, J. T., Fong, S. F. T., Csiszar, K., Giaccia, A., Weninger, W., Yamauchi, M., Gasser, D. L. \& Weaver, V. M. Matrix Crosslinking Forces Tumor Progression by Enhancing Integrin Signaling. Cel/ 139, 891-906 (2009).

63 Weiz, S. M., Medina-Sánchez, M. \& Schmidt, O. G. Microsystems for Single-Cell Analysis. Advanced Biosystems 2, 1700193 (2018).

64 Ghibaudo, M., Trichet, L., Le Digabel, J., Richert, A., Hersen, P. \& Ladoux, B. Substrate Topography Induces a Crossover from 2D to 3D Behavior in Fibroblast Migration. Biophys. J. 97, 357-368 (2009).

65 Clark, P., Connolly, P., Curtis, A. S., Dow, J. A. \& Wilkinson, C. D. Topographical control of cell behaviour. I. Simple step cues. Development 99, 439-448 (1987).

66 Yim, E. K. F., Reano, R. M., Pang, S. W., Yee, A. F., Chen, C. S. \& Leong, K. W. Nanopattern-induced changes in morphology and motility of smooth muscle cells. Biomaterials 26, 5405-5413 (2005).

67 Whitesides, G. M. The origins and the future of microfluidics. Nature 442, 368373 (2006).

68 Douville, N. J., Zamankhan, P., Tung, Y.-C., Li, R., Vaughan, B. L., Tai, C.-F., White, J., Christensen, P. J., Grotberg, J. B. \& Takayama, S. Combination of fluid and solid mechanical stresses contribute to cell death and detachment in a microfluidic alveolar model. Lab on a Chip 11, 609-619 (2011).

69 Rahimzadeh, J., Meng, F., Sachs, F., Wang, J., Verma, D. \& Hua, S. Z. Real-time observation of flow-induced cytoskeletal stress in living cells. Am. J. Physiol. Cell Physiol. 301, C646-652 (2011). 
Imura, Y., Sato, K. \& Yoshimura, E. Micro total bioassay system for ingested substances: assessment of intestinal absorption, hepatic metabolism, and bioactivity. Anal Chem 82, 9983-9988 (2010).

71 Praetorius, H. A. \& Spring, K. R. Bending the MDCK cell primary cilium increases intracellular calcium. The Journal of membrane biology 184, 71-79 (2001).

72 Praetorius, H. A. \& Spring, K. R. Removal of the MDCK cell primary cilium abolishes flow sensing. The Journal of membrane biology 191, 69-76 (2003).

73 Rahimzadeh, J., Meng, F., Sachs, F., Wang, J., Verma, D. \& Hua, S. Z. Real-time observation of flow-induced cytoskeletal stress in living cells. American Journal of Physiology-Cell Physiology 301, C646-C652 (2011).

74 Jang, K. J. \& Suh, K. Y. A multi-layer microfluidic device for efficient culture and analysis of renal tubular cells. Lab Chip 10, 36-42 (2010).

75 Jang, K. J., Cho, H. S., Kang, D. H., Bae, W. G., Kwon, T. H. \& Suh, K. Y. Fluid-shearstress-induced translocation of aquaporin-2 and reorganization of actin cytoskeleton in renal tubular epithelial cells. Integr. Biol. 3, 134-141 (2011).

76 Jang, K. J., Mehr, A. P., Hamilton, G. A., McPartlin, L. A., Chung, S., Suh, K. Y. \& Ingber, D. E. Human kidney proximal tubule-on-a-chip for drug transport and nephrotoxicity assessment. Integr. Biol. 5, 1119-1129 (2013).

77 Baeyens, N., Bandyopadhyay, C., Coon, B. G., Yun, S. \& Schwartz, M. A. Endothelial fluid shear stress sensing in vascular health and disease. The Journal of clinical investigation 126, 821-828 (2016).

78 Kawashima, S. \& Yokoyama, M. Dysfunction of endothelial nitric oxide synthase and atherosclerosis. Arterioscler. Thromb. Vasc. Biol. 24, 998-1005 (2004).

79 Baeyens, N., Mulligan-Kehoe, M. J., Corti, F., Simon, D. D., Ross, T. D., Rhodes, J. M., Wang, T. Z., Mejean, C. O., Simons, M., Humphrey, J. \& Schwartz, M. A. Syndecan 4 is required for endothelial alignment in flow and atheroprotective signaling. Proc. Natl. Acad. Sci. U.S.A 111, 17308-17313 (2014).

80 Conway, D. E., Breckenridge, M. T., Hinde, E., Gratton, E., Chen, C. S. \& Schwartz, M. A. Fluid shear stress on endothelial cells modulates mechanical tension across VE-cadherin and PECAM-1. Curr Bio/ 23, 1024-1030 (2013).

81 Steward, R., Jr., Tambe, D., Hardin, C. C., Krishnan, R. \& Fredberg, J. J. Fluid shear, intercellular stress, and endothelial cell alignment. Am. J. Physiol. Cell Physiol. 308, C657-664 (2015).

82 Hur, S. S., del Alamo, J. C., Park, J. S., Li, Y. S., Nguyen, H. A., Teng, D., Wang, K. C., Flores, L., Alonso-Latorre, B., Lasheras, J. C. \& Chien, S. Roles of cell confluency and fluid shear in 3-dimensional intracellular forces in endothelial cells. Proc Nat/ Acad Sci U S A 109, 11110-11115 (2012).

83 Ohta, S., Inasawa, S. \& Yamaguchi, Y. Alignment of vascular endothelial cells as a collective response to shear flow. Journal of Physics D: Applied Physics 48, 245401 (2015).

84 Lee, H. J., Diaz, M. F., Price, K. M., Ozuna, J. A., Zhang, S., Sevick-Muraca, E. M., Hagan, J. P. \& Wenzel, P. L. Fluid shear stress activates YAP1 to promote cancer cell motility. Nat. Commun. 8, 14122 (2017). 
85 Polacheck, W. J., Charest, J. L. \& Kamm, R. D. Interstitial flow influences direction of tumor cell migration through competing mechanisms. Proc Natl Acad Sci U S A 108, 11115-11120 (2011).

86 Piotrowski-Daspit, A. S., Tien, J. \& Nelson, C. M. Interstitial fluid pressure regulates collective invasion in engineered human breast tumors via Snail, vimentin, and $\mathrm{E}$ cadherin. Integr. Biol. 8, 319-331 (2016).

87 Bhatia, S. N. \& Ingber, D. E. Microfluidic organs-on-chips. Nat Biotech 32, 760 772 (2014).

88 Li, L., Eyckmans, J. \& Chen, C. S. Designer biomaterials for mechanobiology. Nature Materials 16, 1164 (2017). 